\title{
Job stress, sense of coherence and work wellness in an electricity supply organisation
}

\author{
S. Rothmann*, L.J. Steyn and K. Mostert \\ WorkWell: Research Unit for People, Policy and Performance, \\ Faculty of Economic and Management Sciences, North-West University, \\ Private Bag X6001, Potchefstroom 2520, Republic of South Africa \\ bpksr@puk.ac.za
}

Received November 2004

\begin{abstract}
The objective of this study was to test a causal model of work wellness for engineers, technicians and electricians in an electricity supply organisation. An ex post facto correlational design was used. The participants included 38 engineers, 86 technicians and 91 electricians in an electricity supply organisation. The Maslach Burnout Inventory - General Survey, the Utrecht Work Engagement Scale, the Job Stress Inventory and the Orientation to Life Questionnaire were administered. The results showed that job stress, because of job demands and a lack of support, leads to burnout. A strong sense of coherence mediated the relationship between job stress and work wellness (consisting of low burnout and high work engagement).
\end{abstract}

The material described in this article is based upon work supported by the National Research Foundation under Grant number 2053344.

*To whom all correspondence should be addressed.

\section{Introduction}

Modern business is highly competitive, demanding and expensive, and as a result, organisations, management and employees are under constant pressure to achieve higher targets (Brunt, 2000). Organisations everywhere are downsizing, outsourcing and restructuring, leaving workers feeling stressed, insecure, misunderstood, undervalued and alienated. With fewer staff doing more work in nearly every industry, employees experience exhaustion both mentally and physically (Wise, 2001). Moreover, skilled workers for newly developed positions are difficult to find, causing added workloads for employees.

With the transformation to a democracy in South Africa in 1994, the basic need for electricity for all South Africans became evident. This need, together with other macro- and micro-environmental influences, such as government legislation, new technology and changes within the electricity distribution industry, has put pressure on providing affordable energy and related services in order to continually improve performance and enhance development. Furthermore, the sustainability of quality of supply depends on the psychological atmosphere and interpersonal relationships among the specialists concerned as well as with other support services, such as customer services and commercial, capital programme and external consultants/contractors. In many cases, it is taken for granted that technicians and electricians may be called out after normal working hours and even over weekends to attend to customer complaints or faulty equipment (Wise, 2001). These pressures cause stress in the workplace, which could eventually affect the work-related well-being of employees (including burnout and work engagement). Therefore, it is necessary to investigate the factors that contribute to the work-related well-being of employees in the electricity supply industry.

The objective of this study was to test a causal model of work wellness for engineers, technicians and electricians in an electricity supply organisation.

\section{Burnout, work engagement, stress and sense of coherence}

According to Schaufeli and Enzmann (1998), burnout can be defined as a persistent, negative, work-related state of mind (or syndrome) developing in so-called 'normal' individuals, characterised by an array of physical, psychological and attitudinal symptoms, primarily exhaustion, and accompanied by distress, a sense of reduced effectiveness, decreased motivation and the development of dysfunctional personal and societal attitudes and behaviours at work. This psychological condition develops gradually but may remain unnoticed for a long time by the individual involved.

Schaufeli, Leiter, Maslach and Jackson (1996) developed the Maslach Burnout Inventory - General Survey (MBIGS), an adapted version of the original MBI for use outside the human services. The MBI-GS incorporates three dimensions, namely Exhaustion, Cynicism and Professional Efficacy. Exhaustion refers to the depletion or draining of emotional resources and feelings of being overextended. It is accompanied by distress, a sense of reduced effectiveness, 
decreased motivation, and the development of dysfunctional attitudes and behaviours at work. Cynicism refers to the interpersonal dimension of burnout and results in a negative, callous or excessively detached response to various aspects of the job. Professional Efficacy refers to the self-evaluation dimension of burnout and is a feeling of competence, productivity and achievement at work.

From a theoretical point of view one could argue that exhaustion and mental distancing (cynicism) constitute the two key aspects of burnout. Exhaustion refers to the fact that the employee is incapable of performing because all energy has been drained, whereas mental distancing indicates that the employee is no longer willing to perform, because of an increased intolerance for any effort. Mental distancing - or psychological withdrawal from the task - can be seen as an adaptive mechanism to cope with excessive job demands and resulting feelings of exhaustion. However, when this coping strategy becomes a habitual pattern - as in cynicism - it becomes dysfunctional because it disrupts adequate task performance. In its turn, job demands and exhaustion are further increased so that the vicious circle is closed (Schaufeli, 2003). Essentially, incapacity and unwillingness to perform are considered as two sides of the same coin. Indeed, some empirical findings point to the central role of exhaustion and mental distancing as opposed to the third component, lack of professional efficacy.

Relatively low correlations of professional efficacy are observed with exhaustion and cynicism, whereas these two burnout dimensions are correlated relatively strongly (Lee \& Ashforth, 1996). In a similar vein, both 'core of burnout' factors sometimes collapse into one factor (Green, Walkey \& Taylor, 1991). Perhaps, however, this might reflect an artifact, because if all originally positively phrased MBIprofessional efficacy items are rephrased negatively, correlations with exhaustion and cynicism increase substantially (Bouman, Te Brake \& Hoogstraten, 2002). It seems that cynicism develops in response to exhaustion, whereas professional efficacy seems to develop independently and in parallel (Leiter, 1993). Furthermore, professional efficacy is the weakest burnout dimension in terms of significant relationships with other variables (Lee \& Ashforth, 1996). Moreover, several scholars have argued that professional efficacy reflects a personality characteristic rather than a genuine burnout component (Cordes \& Dougherty, 1993; Shirom, 1989).

According to Schaufeli and Bakker (2001), research showed that some individuals, regardless of high job demands and long working hours, do not show symptoms of burnout. Instead, it seemed that they found pleasure in working hard and dealing with job demands. From a positive psychology perspective (Seligman \& Csikszentmihalyi, 2000), such individuals could be described as engaged in their work. The 'positive psychology' paradigm helps to understand the relationship between work, and more specifically goaldirected, structured activity, and well-being (Kelloway \& Barling, 1991). The focus on engagement as the positive antithesis of burnout promises to yield new perspectives on the interventions to promote healthy perceptions, beliefs and physical well-being (Salovey, Rothman, Detweiler \&
Steward, 2000), and to alleviate burnout (Maslach, Schaufeli \& Leiter, 2001).

According to Nelson and Simmons (2003), meaningful work leads to eustress, which would promote engagement even if the situation is demanding. Eustress reflects the extent to which cognitive appraisal of the situation is seen to either benefit or enhance an individual's well-being. To assume the presence of the positive attitudes toward work (e.g., work engagement) by observing the absence of its negative aspects (e.g., burnout), or vice versa, is a simplistic approach to understanding eustress and distress. Therefore, burnout and work engagement (being aspects of workrelated well-being) should be integrated into one model (Rothmann, 2003).

Work engagement is defined as a positive, fulfilling, workrelated state of mind that is characterised by vigour, dedication and absorption. Furthermore, it is not a momentary and specific state, but a more persistent and pervasive affective-cognitive state which is not focussed on a particular object, event, individual or behaviour (Schaufeli, Salanova, González-Romá \& Bakker, 2002). Whereas Maslach and Leiter (1997) argue that engagement is adequately measured by the MBI (i.e., by reversing the MBI scores), Schaufeli et al. (2002) argue that by using the MBI for measuring engagement it is impossible to study its relationship with burnout empirically. Work engagement, as measured by the Utrecht Work Engagement Scale (UWES), consists of three dimensions, namely vigour, dedication and absorption.

Vigour is characterised by high levels of energy and mental resilience while working, as well as a willingness to exert effort and to persist even through difficult times. Dedication is characterised by a sense of significance in one's work, feeling enthusiastic, inspired and proud, and by viewing it as a challenge. Vigour and dedication are the direct opposites of exhaustion and mental distance (cynicism). Absorption comes close to the concept of 'flow' (Nakamura \& Csikszentmihalyi, 2002), an optimal state of experience where focussed attention, a clear mind, unison of body and mind, effortless concentration, complete control, loss of self-consciousness, distortion of time and intrinsic enjoyment are experienced (Schaufeli et al., 2002). Schaufeli and Bakker (2004) provide evidence for the factorial validity of the UWES. Furthermore, they found that the engagement and burnout scales were moderately negatively correlated.

Based on the holistic model of work wellness (Nelson \& Simmons, 2003), burnout and work engagement could be regarded as an outcome of job stress and moderating or mediating individual difference variables (e.g. sense of coherence). This model incorporates a broad range of stressors and individual difference variables that may be salient for cognitive appraisal and coping. The Transactional Process Model (Lazarus, 1991) and the Spielberger StateTrait (STP) model of occupational stress (Spielberger, Vagg \& Wasala, 2003) conceptualize stress as a complex process that consists of three major components, namely a) sources of stress that are encountered in the work environment; b) perception and appraisal of a particular stressor by an 
employee, and c) the emotional reactions that are evoked when a stressor is appraised as threatening.

The STP model of occupational stress focuses on the perceived severity and frequency of occurrence of two major categories of stressor events, job pressures and lack of support (Spielberger et al., 2003). The STP model recognises the importance of individual differences in personality traits in determining how workplace stressors are perceived and appraised. Occupational stress is defined as the mind-body arousal resulting from the physical and/or psychological demands associated with the job. The appraisal of a stressor as threatening leads to the emotional arousal of anxiety and anger, and the associated activation of the autonomic nervous system. If severe and persistent, the resulting physical and psychological strain may cause adverse behavioural consequences (Spielberger et al., 2003). According to Spielberger et al. (2003), employees evaluate their work environment in terms of the severity and frequency of occurrence of specific job demands and pressure and the level of support provided by supervisors, co-workers and organisational policies and procedures. Failing to take the frequency of occurrence of a particular stressor into account may contribute to overestimating the effects of highly stressful situations that rarely occur, while underestimating the effects of moderately stressful events that are frequently experienced.

Various stressors exist in the electricity distribution organisation. Although some of the engineers are not fulltime field workers, they play a key role in the sourcing of new technology, the design of new sub-stations and structures, as well as in the investigation and monitoring of the performance of the plant and networks. Engineers, technicians and electricians play a significant role to ensure a quality and reliable service to customers. These categories of workers are confronted with daily exposure to highvoltage electricity and one error of judgement could lead to serious injury or even fatality to the individual or to coworkers. Other organisational factors that could contribute to burnout are stress because of work overload (Corrigan et al., 1994; Landsbergis, 1988), poor collegial support (Golembiewski \& Munzenrider, 1988), role conflict and role ambiguity (Miller, Ellis, Zook \& Lyles, 1990), as well as a lack of feedback (e.g. participation in decision-making and autonomy).

In 1979, the medical sociologist Aaron Antonovsky wrote that, despite being bombarded by multiple stressors in everyday living and undergoing severe traumatic experiences, there are individuals who are coping quite well and staying healthy. This led to the creation of the concept of salutogenesis (Antonovsky, 1979), emphasising a focus on health rather than on disease (i.e., pathogenesis) (Heim, 1994). Sense of coherence is defined as a global orientation that expresses the extent to which one has a pervasive, enduring though dynamic feeling of confidence that one's internal and external environments are predictable and that there is a high probability that things will work out as well as can reasonably be expected (Antonovsky, 1987). Various research findings showed that sense of coherence is related to the three dimensions of burnout (Basson \& Rothmann, 2002; Gilbar, 1998; Levert, Lucas \& Ortlepp, 2000).
Sense of coherence has been defined as a relatively stable dispositional orientation (Antonovsky, 1987). It is possible that employees with a weak sense of coherence will develop burnout, while those who have developed a strong sense of coherence will show work engagement. Studies (e.g. Antonovsky, 1987; 1993; Rothmann, 2003) have confirmed that a person's sense of coherence is an important component of one's health and well-being. Each person's sense of coherence requires certain inherent prerequisites for coping successfully, which are represented by the concepts of comprehensibility, manageability and meaningfulness (Antonovsky, 1987). Comprehensibility refers to the extent to which persons find or structure their world to be understandable, meaningful, orderly and consistent instead of chaotic, random and unpredictable. Manageability refers to the extent to which people experience events in life as situations that are endurable or manageable and can even be seen as new challenges. Meaningfulness refers to the extent to which one feels that life makes sense on an emotional and not just on a cognitive level, and that life's demands are worthy of commitment. It is, essentially, seeing coping as desirable.

Decades of research on cognitive and behavioural therapy have left no doubt that one's appraisal of a situation plays a key role in one's well-being (Beck, 1997; Clark, 1999; Wells-Federman, Staurt-Shor \& Webster, 2001). Everyone appraises situations in their own distinct way, and those appraisals affect the perceived intensity of a stressor. A pathogenic appraisal can start a vicious circle of stress, whereas a salutogenic appraisal can relieve counterproductive emotions and provide opportunities for coping suitably with the situation. A strong sense of coherence is also related to general well-being (Feldt, 1997) and emotional stability (Mlonzi \& Strümpfer, 1998). This means that individuals with high levels of burnout could be expected to demonstrate weaker levels of sense of coherence. According to Antonovsky (1987), a person with a strong sense of coherence selects the particular coping strategy that seems most appropriate to deal with the stressor being confronted.

Although studies have been carried out regarding the burnout and work engagement of police officers (Storm, 2002), managers in a manufacturing industry (Jansen van Vuuren \& Rothmann, 2002), pharmacists and pharmacists' assistants (Rothmann, Malan \& Rothmann, 2001), burnout and work engagement of employees working in a technical/engineering environment in South Africa have not yet been investigated.

The above discussion leads to the following hypotheses: H1: Job stress predicts burnout (exhaustion and cynicism). $\mathrm{H} 2$ : Sense of coherence mediates the relationship between job stress (input) and burnout and work engagement (output).

\section{Method}

\section{Research design}

An ex post facto correlational design was used to achieve the research objectives (Shaughnessy \& Zechmeister, 1997). 


\section{Participants}

Stratified random samples $(N=215)$ with job categories were taken from engineers, technicians and electricians at a South African electricity distribution organisation. The participants were predominantly male $(98,14 \%)$ and had an education of more that one year post grade 12 . The categories included technicians (39,81\%) and electricians $(42,13 \%)$ within the non-managerial/supervisory function. The mean age of the participants was 40,5 years. The majority (62,96\%) of participants' length of service was more than 10 years, and $67,13 \%$ of them did standby duties.

\section{Instruments}

The Maslach Burnout Inventory - General Survey (MBI-GS) (Schaufeli et al., 1996) was used to measure burnout. Two of the sub-scales were used, namely Exhaustion (five items, e.g. 'I feel used up at the end of the workday'), and Cynicism (five items, e.g. 'I have become less enthusiastic about my work'). All items were scored on a seven-point frequency rating scale ranging from 0 (never) to 6 (daily). Steyn (2004) confirmed the two-factor structure of the MBIGS for employees in an electricity supply organisation, but recommended that Item 13 be dropped from the questionnaire. Internal consistencies (Cronbach coefficient alphas) reported by Schaufeli et al. (1996) and Storm (2002) varied from 0,87 to 0,89 for Exhaustion, and 0,73 to 0,84 for Cynicism. Test-retest reliabilities after one year were 0,65 (Exhaustion) and 0,60 (Cynicism) (Schaufeli et al., 1996).

The Utrecht Work Engagement Scale (UWES) (Schaufeli et al., 2002) was used to measure the levels of engagement of participants. The UWES measures levels of engagement on a 17-item seven-point frequency rating scale, ranging from 0 (never) to 6 (every day). Three dimensions can be distinguished, namely vigour, dedication and absorption. Examples of statements relating to the three dimensions are the following: 'I am bursting with energy in my work' (Vigour); 'I find my work full of meaning and purpose' (Dedication); and 'When I am working, I forget everything around me' (Absorption). Engaged individuals are characterised by high levels of vigour and dedication, as well as by elevated levels of absorption. Steyn (2004) confirmed a one-factor model of work engagement in a South African study.

The Job Stress Inventory (JSI) (Steyn, 2004) was used to measure job stressors. Each of the 30 items describes a jobrelated stressor event and assesses both the perceived severity and the frequency of occurrence of that event. The JSI is scored on a nine-point frequency and intensity rating scale, varying from 0 (low) to 9 (high). Factor analysis with a varimax rotation of the items identified two underlying factors, namely Stress - Job Demands and Stress - Lack of Support. The alpha coefficients of the two scales were 0,89 and 0,78 respectively.

The Orientation to Life Questionnaire (OLQ) (Antonovsky, 1987) was used to measure the participants' sense of coherence. The OLQ consists of 29 items. Antonovsky (1993) reported Cronbach alpha coefficients of the OLQ in 29 research studies varying between 0,85 and 0,91 . Test- retest reliability studies found coefficients between 0,41 and 0,97 (Antonovsky, 1993). Rothmann (2000) reported an alpha coefficient of 0,89 for the OLQ, which may be regarded as acceptable (Nunnally \& Bernstein, 1994). In terms of the construct validity of the OLQ, it was found that a negative relationship exists between the OLQ and experienced stress, and that the OLQ correlates negatively with the 'State-Trait Anxiety Inventory-Trait' and the 'Beck Depression Inventory’ (Frenz, Carey \& Jorgensen, 1993).

\section{Statistical analysis}

The statistical analysis was carried out with the SPSS program (SPSS Inc., 2003) and the Amos program (Arbuckle, 1999). Exploratory factor analyses and Cronbach alpha coefficients were used to assess the validity and reliability of the constructs which were measured in this study. Descriptive statistics (e.g. means, standard deviations, skewness and kurtosis) and inferential statistics were used to analyse the data.

Exploratory factor analyses were carried out to determine the construct validity of the measuring instruments. The following procedure was followed: Firstly, a simple principal components analysis was conducted on the constructs which form part of the measurement model, including a) burnout and work engagement; b) job stress, and c) sense of coherence. The eigenvalues and scree plot were studied to determine the number of factors. Secondly, a principal components analysis with a direct oblimin rotation was conducted if factors were related. Thirdly, a principal component analysis with a varimax rotation was used if the obtained factors were not related (Tabachnick \& Fidell, 2001).

Pearson product-moment correlation coefficients were used to specify the relationship between the different variables. A cut-off point of $p=0,05$ was set for the statistical significance of the results. Effect sizes (Cohen, 1988; Steyn, 1999) were used in addition to statistical significance to determine the practical significance of relationships. Effect sizes indicate whether obtained results are important, while statistical significance may often show results which are of little practical relevance (Steyn, 1999). A cut-off point of 0,30 (medium effect) (Cohen, 1988) was set for the practical significance of correlation coefficients.

Structural equation modelling (SEM) methods as implemented in AMOS (Arbuckle, 1999) were used to test the causal model of work wellness, using the maximum likelihood method. Hypothesized relationships were tested empirically for goodness of fit with the sample data. Among the fit indices produced by the AMOS programme is the Chi-square statistic $\left(\chi^{2}\right)$ which is the test of absolute fit of the model. However, the $\chi^{2}$ value is sensitive to sample size. Therefore, additional goodness-of-fit indices such as the Goodness of Fit Index (GFI), the Adjusted Goodness of Fit Index (AGFI), the Normed Fit Index (NFI), the Comparative Fit Index (CFI), the Tucker-Lewis Index (TLI) and the Root Means Square Error of Approximation (RMSEA) were used in this study. 


\section{Results}

\section{Construct validity of the measuring instruments}

To prepare the data for the purpose of testing a causal model of work wellness of employees in the electricity supply industry, exploratory factor analyses were carried out on the scales of the MBI-GS and UWES as well as the JSI, using SPSS (SPSS Inc. 2003). First, a simple principal component analysis was conducted on the scales of the MBI-GS and UWES. The scree plot suggested the extraction of two factors (which explained 79,03\% of the total variance). Principal component analysis with an Oblimin rotation resulted in two correlated factors $(r=-0,23)$, namely Burnout, including Exhaustion (loading $=0,91$ ) and Cynicism (loading $=0,86$ ), and Extended Work Engagement, including Vigour/Dedication/Absorption (loading $=0,58$ ) and Professional Efficacy (loading = 0,96).

Next, a simple principal component analysis was conducted on the scales of the JSI. The scree plot and eigenvalues provided evidence for a two-factor solution which explained $41,50 \%$ of the total variance. Principal component analysis with an Oblimin rotation resulted in two correlated factors $(r$ = -0,57), namely Stress - Job Demands and Stress - Lack of Support.

The first factor, Stress - Job Demands, included the following items (loadings are showed in brackets): working overtime $(0,61)$; assignment of new or unfamiliar duties $(0,78)$; inadequate support by supervisor $(0,60)$; dealing with crisis situations $(0,81)$; performing tasks not in the job description $(0,68)$; inadequate or poor quality equipment $(0,48)$; assignment of increased responsibility $(0,68)$; periods of inactivity $(0,48)$; difficulty getting along with the supervisor $(0,62)$; making critical on-the-spot decisions $(0,61)$; poor or inadequate supervision $(0,56)$; noisy work area $(0,45)$; frequent changes from boring to demanding activities $(0,43)$; and conflict with other departments $(0,45)$. The second factor, Stress - Lack of Support included the following items: lack of opportunity for advancement $(0,56)$; experiencing negative attitudes toward the organisation $(0,68)$; insufficient personnel to handle an assignment $(0,64)$; fellow workers not doing their job $(0,61)$; lack of participation in policy-making decisions $(0,71)$; inadequate salary $(0,74)$; competition for advancement $(0,65)$; excessive paperwork $(0,50)$; covering work for another employee $(0,53)$, and poorly motivated co-workers $(0,77)$.

\section{Descriptive statistics}

Table 1 shows the descriptive statistics and the Cronbach alpha coefficients of the MBI-GS, UWES, JSI and OLQ.

The scores on the MBI-GS, UWES, JSI and OLQ seem to satisfy the assumptions of uni-variate normality. The Cronbach alpha coefficients of all measuring instruments are considered to be acceptable compared to the guideline of $\alpha$ $>$ 0,70 (Nunnally \& Bernstein, 1994).

A model of work wellness

The product-moment correlation coefficients between the MBI-GS, UWES, JSI and OLQ are reported in Table 2.

Table 1: Descriptive statistics and alpha coefficients of the MBI-GS, UWES, JSI and OLQ

\begin{tabular}{|c|c|c|c|c|c|}
\hline Scale & Mean & $S D$ & Skewness & Kurtosis & $\alpha$ \\
\hline Exhaustion & 12,09 & 7,50 & 0,55 & $-0,45$ & 0,90 \\
\hline Cynicism & 8,37 & 5,64 & 0,63 & $-0,23$ & 0,75 \\
\hline Engagement & 55,85 & 16,57 & $-0,80$ & 0,47 & 0,93 \\
\hline Stress: Job Demands & 66,27 & 22,58 & $-0,09$ & $-0,80$ & 0,89 \\
\hline Stress: Lack of Support & 56,62 & 16,89 & $-0,40$ & $-0,31$ & 0,86 \\
\hline Sense of Coherence & 134,90 & 20,61 & $-0,35$ & 1,01 & 0,86 \\
\hline
\end{tabular}

Table 2: Product-moment correlation coefficients between the MBI-GS, UWES, JSI and OLQ

\begin{tabular}{|c|c|c|c|c|c|}
\hline Construct & 1 & 2 & 3 & 4 & 5 \\
\hline 1. Exhaustion & - & - & - & - & - \\
\hline 2. Cynicism & $0,61^{*++}$ & - & - & - & - \\
\hline 3. Work Engagement & $-0,38^{*+}$ & $-0,50^{*++}$ & - & - & - \\
\hline 4. Stress: Demands & $0,41^{*+}$ & $0,39^{*+}$ & $-0,20^{*}$ & - & - \\
\hline 5. Stress: Lack of Support & $0,40^{*+}$ & $0,44^{*+}$ & $-0,25^{*}$ & $0,67^{*++}$ & - \\
\hline 6. Sense of Coherence & $-0,30^{*+}$ & $-0,42^{*+}$ & $0,44^{*+}$ & $-0,39^{*+}$ & $-0,32^{*+}$ \\
\hline
\end{tabular}

$* p \leq 0,01$ statistically significant

+ Correlation is practically significant $r>0,30$ (medium effect)

++ Correlation is practically significant $r>0,50$ (large effect) 
As can be seen in Table 2, Sense of Coherence is negatively related to Stress - Job Demands and Stress - Lack of Support (practically significant, medium effect). Sense of Coherence is also negatively related to Exhaustion, Cynicism and Work Engagement (practically significant, medium effect). Stress - Lack of Support and Stress - Job Demands are practically significantly related to Exhaustion and Cynicism (both medium effects), and statistically significantly related to Work Engagement.

A more comprehensive test of the hypothesised relationships can be accomplished with structural equation modelling (SEM) methods as implemented by AMOS (Arbuckle, 1999). A model was constructed based upon the consensus of findings from a review of the literature on burnout and work engagement, as it bears on the work environment of engineers, technicians and electricians. A model, including hypothesised relationships, was tested with SEM analysis. Results indicated that the model fitted adequately to the data: $\chi^{2}(6, N=218)=11,66, p<0,07 ; \chi^{2} / \mathrm{df}=1,94$; $\mathrm{GFI}=0,98 ; \mathrm{AGFI}=0,94 ; \mathrm{CFI}=0,99 ; \mathrm{NFI}=0,97$; $\mathrm{TLI}=$ 0,97 , and RMSEA $=0,07$.

The standardised regression coefficients are shown in the model in Figure 1. As can be seen there, the path from job stress to sense of coherence was statistically significant. Therefore, perceived stress because of job demands and a lack of support contributed to a weak sense of coherence of employees. Job stress had an impact on burnout. Furthermore, sense of coherence mediated the effects of job stress on work wellness, which is a second-order factor, comprising of burnout (negative loading) and engagement. The model indicates that job stress has a strong influence on both burnout and engagement and that this effect is both direct and indirect.

\section{Discussion}

This study set out to test a causal model of work wellness for employees in an electricity supply organisation, using an ex post facto correlational design. The sample consisted of 218 engineers, technicians and electricians in an electricity supply organisation. A good fit was found for a model in which perceived job stress (because of job demands and a lack of support) predicts burnout of employees. Sense of coherence played an important role in the link between job stress and output variables. It mediated the effects of job stress on work wellness (a second-order factor consisting of burnout and work engagement). Employees with a strong sense of coherence were found to experience less burnout and more work engagement, presumably because stimuli from the environment are perceived as making cognitive sense, as being under control of both the employee and significant others, and as being motivationally relevant and meaningful.

A two-factor structure of work wellness (consisting of burnout and work engagement) was found in this study. This result confirms previous findings (Schaufeli \& Bakker, 2004). Although this patterning in two factors has a conceptual underpinning, the impact of method factors should not be underrated. Engagement is measured by positively worded items, while exhaustion and cynicism are measured by negatively worded items. This similarity could easily lead to an overestimation of the real correlation of items with similar wordings (e.g., negative statements) and to an underestimation of the real correlation of items with a different format. Low levels of burnout were related to high levels of engagement. Therefore, the findings of Schaufeli, Martinez, Pinto, Salanova and Bakker (2002) that burnout and engagement are related but distinct concepts were confirmed in this study.

This study resulted in two factors of job stress, namely job demands and lack of support. These factors correspond with the two factors distinguished by Spielberger et al. (2003) (i.e. job demands and pressure and the level of support provided by supervisors, co-workers and organisational policies and procedures). Sense of coherence was negatively related to burnout, which confirms the results of Basson and Rothmann (2002) and Wissing, De Waal and De Beer (1992). Sense of coherence was positively related to work engagement.

The structural model that was developed for the purpose of this study showed that job stress had a direct effect on burnout (consisting of exhaustion and cynicism). Job stress and sense of coherence explained $62 \%$ of the variance in burnout. Furthermore, job stress had an indirect effect on work wellness (which is a second-order factor consisting of burnout and work engagement). Employees who have a strong sense of coherence probably perceive that they are able to cope with job stress, which makes it possible to experience eustress and work engagement (Nelson \& Simmons, 2003). Employees with a strong sense of coherence experience less burnout and more work engagement, presumably because stimuli from the environment are perceived as making cognitive sense (comprehensible), as under being control of both the employee and legitimate others (manageable), and as being motivationally relevant and meaningful (meaningfulness).

Employees who have a weak sense of coherence probably find it difficult to structure their world to be understandable, orderly and consistent. They tend to experience life events as unmanageable and perceive that they lack the resources to meet the demands, and they might feel that life does not make sense on an emotional level (Antonovsky, 1987). It is understandable that they would perceive situations as stressful. Sense of coherence mediated the effects of job stress on work wellness and explained $26 \%$ of the variance in work wellness (consisting of both burnout and work engagement).

This study had various limitations. Firstly, the research design was ex post facto (i.e. non-experimental), which makes it logically impossible to prove the causality of the relationships obtained. Secondly, self-report measures were exclusively relied on. Therefore, at least part of the common variance of the measures could be attributed to method variance (Schaufeli, Maslach \& Marek, 1993). Thirdly, the findings cannot be generalised to engineers, technicians and electricians in other electricity distribution organisations, due to the sample size and organisation specifics. 


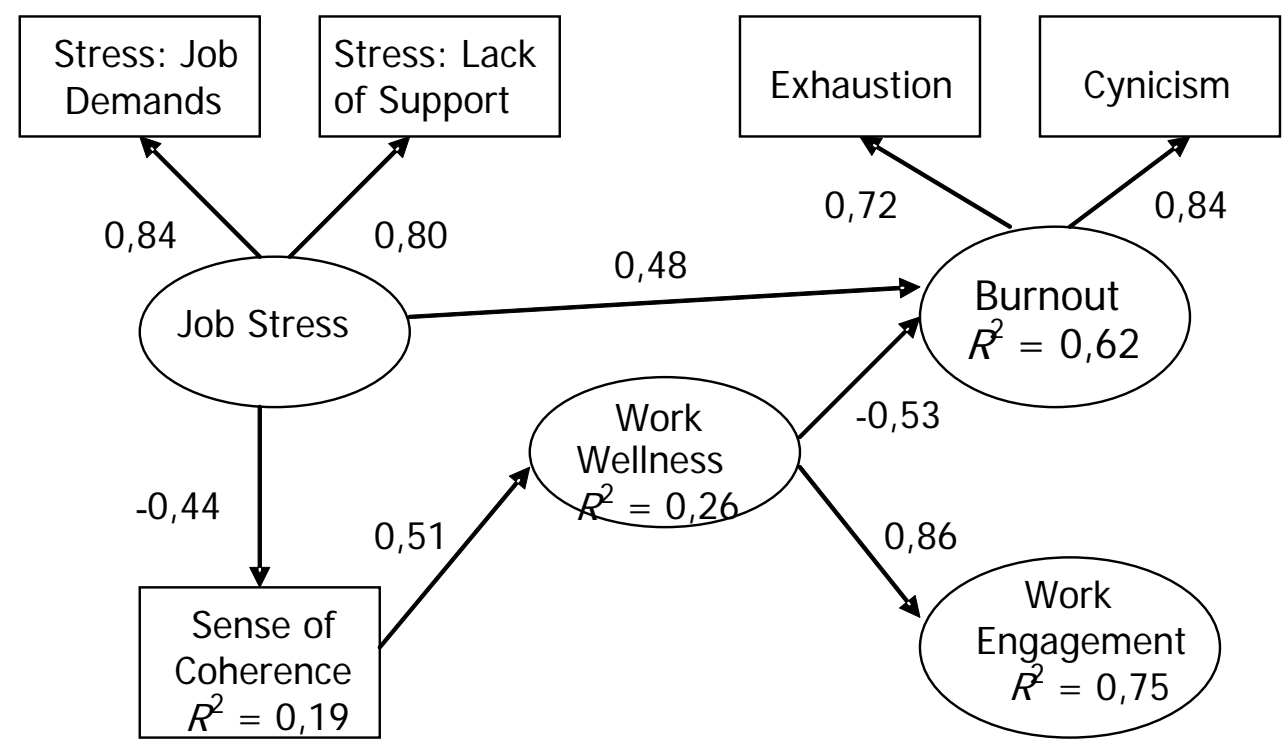

Figure 1. Maximum likelihood estimates for the model of work wellness, $\mathbf{N}=215$ (standardised solution). (Note: All factor loadings and path coefficients are significant, $p<0,01$ ).

\section{Recommendations}

In order to alleviate burnout, the electricity distribution organisation should design and implement planned interventions to prevent job stress. Although it is important to assist individual engineers, technicians or electricians whose psychological well-being is affected by their work, primary and secondary interventions in addition to tertiary interventions should be implemented. The intention is to make the organisation inherently less stressful. Since stress because of job demands and a lack of support play a central role in burnout, it is necessary to implement preventative organisation-based solutions to tackle the problem of lack of support.

The organisation could manage the behaviour of employees' with a weak sense of coherence by giving information in a constant, structured, ordered and understandable format. Employees should be able to identify their roles within the greater whole and as such improve the comprehensibility component of sense of coherence. Also, it is important to focus on employees' coping strategies. Training and development programmes that are directed at developing sense of coherence and coping with stress should be compiled and evaluated.

Several suggestions for future research have been derived from the present findings. It is necessary to unpack sense of coherence as a latent variable to refine the model of work wellness. Future studies should use a more appropriate design (e.g. a longitudinal or experimental design), large samples and adequate statistical techniques (e.g. structural equation modelling).

\section{References}

Antonovsky, A. 1979. Health, stress, and coping: New perspectives on mental and physical well-being. San
Francisco, CA: Jossey-Bass.

Antonovsky, A. 1987. Unraveling the mystery of health: How people manage stress and stay well. San Francisco, CA: Jossey-Bass.

Antonovsky, A. 1993. 'The structure and properties of the sense of coherence scale', Social Science and Medicine, 36: 725-733.

Arbuckle, J.L. 1999. Amos 4.0. Chicago, IL: Smallwaters.

Basson, M.J. \& Rothmann, S. 2002. 'Sense of coherence, coping and burnout of pharmacists', South African Journal of Economic and Management Sciences, 5(1): 35-62.

Beck, A.T. 1997. 'The past and future of cognitive therapy', Journal of Psychotherapy Practice, 6(4): 276-284.

Bouman, A.H., Te Brake, H. \& Hoogstraten, J. 2002. 'Significant effects due to rephrasing the Maslach Burnout Inventory's personal accomplishment items', Psychological Reports, 91: 825-826.

Brunt, G. 2000. 'Burnout'. [online] URL: http:// www.corporatetraining.co.za/news3 htm. Retrieved October 10, 2002.

Clark, D.M. 1999. 'Anxiety disorders. Why they persist and how to treat them', Journal of Psychotherapy Practice, 37(1): 25-27.

Cohen, J. 1988. Statistical power analysis for the behavioral sciences ( $2^{\text {nd }}$ Edition $)$. Orlando, CA: Academic Press.

Cordes, C.L. \& Dougherty, T.W. 1993. 'A review and an integration of research on job burnout', Academy of Management Review, 18: 621-656. 
Corrigan, P.W., Holmes, E.P., Luchins, D., Buican, B., Basit, A.J. \& Parks, J. 1994. 'Staff burnout in a psychiatric hospital: A cross-lagged panel design', Journal of Organizational Behavior, 15: 65-74.

Feldt, T. 1997. 'The role of sense of coherence in well-being at work: Analysis of main and moderator effects', Work and Stress, 11: 134-147.

Frenz, A.W., Carey, M.P. \& Jorgensen, R.S. 1993. 'Psychometric evaluation of Antonovsky's sense of coherence scale’, Psychological Assessment, 5: 145-153.

Gilbar, O. 1998. 'Relationship between burnout and sense of coherence in health social workers', Social Work in Health Care, 26(3): 39-49.

Golembiewski, R.T. \& Munzenrider, R.F. 1988. Phases of burnout: Development in concepts and applications. New York: Praeger.

Green, D.E., Walkey, F.H. \& Taylor, A.J.W. 1991. 'The three-factor structure of the Maslach Burnout Inventory', Journal of Social Behavior and Personality, 6: 453-472.

Heim, E. 1994. 'Salutogenesis versus pathogenesis: A new approach to an old wisdom', Social Psychology of Health and Illness, 124: 1267-1275.

Jansen van Vuuren, J.A. \& Rothmann, S. 2002. 'The relationship between psychological strengths, coping and burnout of senior managers in a manufacturing industry'. Paper presented at the $14^{\text {th }}$ Conference of the South African Institute for Management Scientists, Pretoria.

Kelloway, E.K. \& Barling, J. 1991. 'Job characteristics, role stress and mental health', Journal of Occupational Psychology, 64: 291-304.

Landsbergis, P.A. 1988. 'Occupational stress among health care workers: A test of the job demands - control model', Journal of Organizational Behavior, 9: 217-239.

Lazarus, R.S. 1991. Psychological stress and the coping process. New York: McGraw-Hill.

Lee, R.T. \& Ashforth, B.E. 1996. 'A meta-analytic examination of the correlates of the three dimensions of job burnout', Journal of Applied Psychology, 81: 123-133.

Leiter, M.P. 1993. 'Burnout as a developmental process: Consideration of models'. In Schaufeli, W.B. Maslach, C. \& Marek, T. (Eds.). Professional burnout: Recent developments in theory and research. Washington, DC: Taylor \& Francis, pp.237-250. Series in applied psychology: Social issues and questions.

Levert, T., Lucas, M. \& Ortlepp, K. 2000. 'Burnout in psychiatric nurses: Contributions of the work environment and a sense of coherence,' South African Journal of Psychology, 30: 36-43.
Maslach, C., Schaufeli, W.B. \& Leiter, M.P. 2001. 'Job burnout', Annual Review of Psychology, 52: 397-422.

Maslach, C. \& Leiter, M.P. 1997. The truth about burnout. San Francisco, CA: Jossey-Bass.

Miller, K.I., Ellis, B.H., Zook, E.G. \& Lyles, J.S. 1990. 'An integrated model of communication, stress, and burnout in the workplace', Communication Research, 17: 200-326.

Mlonzi, E.N. \& Strümpfer, D.J.W. 1998. 'Antonovsky's sense of coherence scale and 16PF second-order factors', Social Behavior and Personality, 26: 39-50.

Nakamura, J. \& Csikszentmihalyi, M. 2002. 'The concept of flow’. In Snyder, C.R. \& Lopez, S.J. (Eds.). Handbook of positive psychology. Oxford, UK: Oxford University Press, pp.715-728.

Nelson, D.L. \& Simmons, B.L. 2003. 'Health psychology and work stress: A more positive approach'. In Quick, J.C. \& Tetrick, L.E. (Eds.). Handbook of occupational health psychology. Washington, DC: American Psychological Association, pp. 97-119.

Nunnally, J.C. \& Bernstein, I.H. 1994. Psychometric theory ( $3^{\text {rd }}$ Edition). New York: McGraw-Hill.

Rothmann, S. 2003. 'Burnout and engagement: A South African perspective', South African Journal of Industrial Psychology, 29(4): 16-25.

Rothmann, S. 2000. 'Sense of coherence, locus of control, self-efficacy and job satisfaction.' Paper presented at the $28^{\text {th }}$ International Congress of Psychology, Stockholm, Sweden.

Rothmann, S., Malan, A.M. \& Rothmann, J.C. 2001. 'Sense of coherence, coping and burnout in a corporate pharmacy group'. Paper presented at the $7^{\text {th }}$ Annual PsySSA Conference, Johannesburg.

Salovey, P., Rothman, A.J., Detweiler, J.B. \& Stewart, W.T. 2000. 'Emotional states and physical health', American Psychologist, 55: 110-121.

Schaufeli, W.B. 2003. 'Past performance and future perspectives of burnout research', South African Journal of Industrial Psychology, 29(4): 1-15.

Schaufeli, W.B. \& Bakker, A.B. 2001. 'Werk en welbevinden: Naar een positieve benadering in de arbeidsen gezondheidspsychologie' [Work and wellbeing: Towards a positive occupational health psychology], Gedrag en Organizatie, 14: 229-253.

Schaufeli, W.B. \& Bakker, A.B. 2004. 'Job demands, job resources, and their relationship with burnout and engagement: A multi-sample study', Journal of Organizational Behavior, 25: 1-23.

Schaufeli, W.B. \& Enzmann, D. 1998. The burnout companion to study and practice: A critical analysis. 
London: Taylor \& Francis.

Schaufeli, W.B., Leiter, M.P., Maslach, C. \& Jackson, S.E. 1996. 'MBI - General Survey'. In Maslach, C., Jackson, S.E. \& Leiter, M.P. (Eds.). Maslach Burnout Inventory Manual. (3 $3^{\text {rd }}$ Edition). Palo Alto, CA: Consulting Psychologists Press.

Schaufeli, W.B., Martinez, I., Pinto, A.M., Salanova, M. \& Bakker, A.B. 2002. 'Burnout and engagement in university students: A cross-national study', Journal of Cross-Cultural Psychology, 33: 464-481.

Schaufeli, W.B., Maslach, C. \& Marek, T. (Eds.). 1993. Professional burnout. Washington, DC: Taylor \& Francis.

Schaufeli, W.B., Salanova, M., González-Romá, V. \& Bakker, A.B. 2002. 'The measurement of engagement and burnout: A confirmative analytic approach', Journal of Happiness Studies, 3: 71-92.

Seligman, M.E.P. \& Csikszentmihalyi, M. 2000. 'Positive psychology: An introduction', American Psychologist, 55: 5-14.

Shaugnessy, J.J. \& Zechmeister, E.B. 1997. Research methods in psychology ( $4^{\text {th }}$ Edition). New York: McGrawHill.

Shirom, A. 1989. 'Burnout in work organizations'. In Cooper, C.L. \& Robertson, I.T. (Eds.). International Review of Industrial and Organizational Psychology 1989. Chichester: Wiley, pp. 25-48.

Spielberger, C.D., Vagg, P.R. \& Wasala, C.F. 2003. 'Occupational stress: Job pressures and lack of support'. In Quick, J.C. \& Tetrick, L.E. (Eds.). Handbook of occupational health psychology. Washington, DC: American Psychological Association, pp. 185-200.

SPSS Inc. 2003. SPSS 12.0 for Windows. Chicago, IL: Author.

Steyn, H.S. 1999. Praktiese betekenisvolheid: Die gebruik van effekgroottes. Wetenskaplike bydraes - Reeks B: Natuurwetenskappe Nr. 117. Potchefstroom: PU vir CHO.

Steyn, L.J. 2004. 'Sense of coherence, job stress, coping and burnout in an electricity supply organisation'. Unpublished Masters dissertation, North-West University, Potchefstroom.

Storm, K. 2002. 'Burnout and engagement in the South African Police Service'. Unpublished Ph.D. thesis, PU for CHE, Potchefstroom.

Tabachnick, B.G. \& Fidell, L.S. 2001. Using multivariate statistics. $4^{\text {th }}$ Edition. Boston, MA: Allyn \& Bacon.

Wells-Federman, C.L., Stuart-Shor, E. \& Webster, A. 2001. 'Cognitive therapy: Applications for health promotion, disease prevention, and disease management', Journal of Clinical Psychology, 36: 93-114.
Wise, D. 2001. 'Employee burnout taking major toll on productivity', Los Angeles Business Journal. [online] URL:http://www.findarticles.com/cf-/m5072/2823/76613647/print.jhtml. Retrieved October 8, 2002.

Wissing, M.P., De Waal, M. \& De Beer, I. 1992. 'Sense of coherence and stress symptomatology'. Paper presented at $25^{\text {th }}$ International Congress of Psychology, Brussels, Belgium. 